\title{
Blends of Thermotropic Liquid Crystalline Polymer with a Flexible Side Group and Poly(butylene terephthalate)
}

\author{
Jin-Hae CHANG ${ }^{\dagger}$ and Richard J. FARRIs* \\ Polymer Science and Engineering Department, Kum-Oh \\ University of Technology, Gumi 730-701, Korea \\ * Polymer Science and Engineering Department, University \\ of Massachusetts, Amherst, MA 01003, U.S.A.
}

(Received December 26, 1994)

\begin{abstract}
Blends of thermotropic liquid crystalline polymer (TLCP) with poly(butylene terephthalate) (PBT) were prepared by coprecipitation from a common solvent. The blends (5\%, $10 \%$, and $20 \% \mathrm{LCP} / \mathrm{PBT}$ ) were processed for fiber spinning to examine tensile properties in various draw ratios. To find optimized processing conditions, such as retention time and temperature in capillary rheometer, thermal treatment of the fibers was carried out in DSC at $250^{\circ} \mathrm{C}$ and $290^{\circ} \mathrm{C}$, respectively. There were no significant chemical changes at $250^{\circ} \mathrm{C}$. The fibers were extruded through a capillary die at $245^{\circ} \mathrm{C}$ to produce a monofilament. In all blends, LCP domains in PBT matrix were very well dispersed and showed fine spherical particles. The values of ultimate strength were maximum at the $5 \mathrm{wt} \%$ level of LCP in the blends, and then decreased when LCP content was increased up to $20 \%$. Initial modulus monotonically increased with LCP content in all cases.

KEY WORDS Blends / Thermotropic Liquid Crystalline Polymers / Spinning/

Mechanical Properties /
\end{abstract}

Up to now, a common and important technology for polymer fiber composites is the addition of reinforcing fibers to a polymer matrix to improve mechanical properties. ${ }^{1,2}$ But the addition of these fibers to a polymer melt results in substantial increase in viscosity, making more difficult and energy intensive. Otherwise the addition of liquid crystalline polymers as reinforcing materials in engineering thermoplastics enhances their mechanical performance and processability, because the liquid crystal (nematic) phase in the blends has intrinsically low melt viscosity and tendency toward easy orientation in the flow direction. $^{3-5}$

The blends of main chain thermotropic liquid crystalline polymers (TLCPs) with commercial thermoplastics have been studied systematically in many laboratories and else-

\footnotetext{
† To whom correspondence should be addressed.
}

where, especially, the well known polyblend is TLCP prepared by Tennessee Eastman Kodak, a copolymer of $p$-hydroxybenzoic acid with ethylene terephthalate (HBA-ETP) ${ }^{6,7}$ in poly(ethylene terephthalate) (PET) and a copolymer of 6-hydroxy-2-naphthoic acid with $p$-hydroxybenzoic acid (HNA-HBA) in polycarbonate matrix..$^{3,4,8,9}$ The blends of a side-group LCP with thermoplastic resins have been studied by some authors. ${ }^{10}$ Heitz et al. ${ }^{11}$ describe that the side-group LCP in blends not only improves solubility and reduced transition temperatures, but also changes the morphology of their blends. This implies that the existence of the flexible side group in the LCP plays an important role in reinforcing the thermoplastic matrix.

This work describes the tensile properties of blends based on TLCP with a flexible side 
group and PBT as a matrix polymer. To improve tensile properties, we tried to find optimum processing parameters such as draw ratio and the amount of LCP content in a matrix polymer. The morphological properties of blends have been studied on a scanning electron microscope.

\section{EXPERIMENTAL}

\section{Synthesis of the Polymer}

The polymer, THE-3, which has a flexible side group on a mesogenic hydroquinone ring in the main chain, was prepared by solution polymerization of the trioxyethylene substituted hydroquinone, ethylene glycol and terephthaloyl chloride. ${ }^{12}$ TLCP is a copolymer consisting of $60 \mathrm{~mol} \%$ THE-3 and $40 \mathrm{~mol} \%$ PET. PET and PBT for this work were obtained from the AKZO Company and TLCP was supplied by Dr. Lenz's lab. of the University of Massachusetts. The general properties of the polymers are tabulated in Table I. The chemical structures of THE-3, PET, and TLCP are as follows;
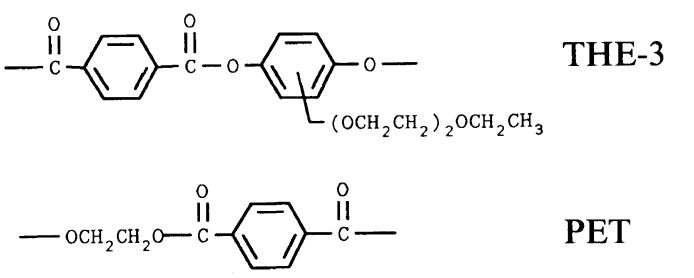

PET

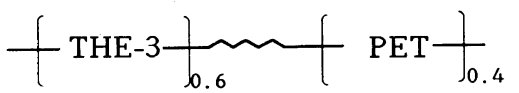

TLCP

\section{Solution Blending}

TLCP and PBT were dissolved in trifluoroacetic acid at room temperature. The concentration of the solution was $5 \%$ by weight to avoid agglomeration of LCP itself in a solvent. ${ }^{13,14}$ Thereafter the polymer solution was coprecipitated in acetone drop by drop with vigorous agitation. We washed the white precipitants with $5 \% \mathrm{NaHCO}_{3}$ and water, twice, respectively. The blends were dried in
Table I. Properties of THE-3, TLCP, and PBT

\begin{tabular}{lcccc}
\hline Polymer & $\eta_{\text {inh }}{ }^{\mathrm{a}}$ & $T_{\mathrm{m}} /{ }^{\circ} \mathrm{C}$ & $T_{\mathrm{i}} /{ }^{\circ} \mathrm{C}$ & $\bar{M}_{n}$ \\
\hline THE-3 & 1.07 & 195 & 248 & - \\
TLCP & 0.65 & 228 & 270 & - \\
PBT & - & 224 & - & 33,000
\end{tabular}

a Inherent viscosity was measured at $50^{\circ} \mathrm{C}$ at $0.5 \mathrm{~g} \mathrm{dL}^{-1}$ in 4-chlorophenol.

a vacuum oven at $110^{\circ} \mathrm{C}$ for $2-3$ days. In blending, LCP concentration for fibers was varied in the range of $5-20 \mathrm{wt} \%$.

For simplicity, the blends are indicated as $0 \% \mathrm{LCP} / \mathrm{PBT}, 5 \% \mathrm{LCP} / \mathrm{PBT}, 10 \% \mathrm{LCP} / \mathrm{PBT}$, and so on. LCP and PBT represent the polymer components used to prepare the blends and the numbers denote the amounts of LCP in the blend in weight percent. For example, $0 \%$ LCP/PBT represents pure PBT while $10 \%$ LCP/PET indicates that the blend contains $10 \mathrm{wt} \% \mathrm{LCP}$.

\section{Extrusion}

The dried blends were pressed at $210^{\circ} \mathrm{C}$, $2500 \mathrm{~kg} \mathrm{~cm}^{-2}$ for $2-3 \mathrm{~min}$ on a hot press. The film-type blends were dried in a vacuum oven at $110^{\circ} \mathrm{C}$ for $24 \mathrm{~h}$. The films were stretched through a die of capillary rheometer (INSTRON 3210 ) at $245^{\circ} \mathrm{C}$. From the capillary rheometer, the extrudates were stretched by a take-up machine. The mean residence time in capillary rheometer was about $4-5$ min.

\section{Characterization Method}

Thermal properties of the blends were studied under an $\mathrm{N}_{2}$ atmosphere on a Du Pont 910 differential scanning calorimeter (DSC). Heating and cooling rates of $20^{\circ} \mathrm{C} \mathrm{min}^{-1}$ were used. All curves and data showed were obtained from the first scanning. Thermal stability was examined on a thermogravimetric analyzer (TGA) (Du Pont 910) at a heating rate of $20^{\circ} \mathrm{Cmin}^{-1}$. Optical microscopic studies were performed using a Zeiss polarizing optical microscope with a hot stage (Mettler FP-2). 
The tensile properties of the extrudates were measured on an Instron Mechanical Tester with a crosshead speed $10 \mathrm{~mm} \mathrm{~min}^{-1}$. Each tensile property was averaged for 6 tests. Experimental uncertainty in tensile strength and modulus was $\pm 1 \mathrm{MPa}$ and $\pm 0.05 \mathrm{GPa}$, respectively.

A JEOL (JSM-35C) scanning electron microscope (SEM) was used to characterize morphology of the films and fibers of the blends. All samples were fractured perpendicularly to the stretch direction in liquid nitrogen and fractured surfaces were sputtered with gold using an Sputter Coater for enhanced conductivity.

\section{RESULTS AND DISCUSSION}

\section{Thermal Properties}

Figure 1 shows DSC traces of the pure polymers (PBT and LCP) and their blends obtained by solution precipitation. The crystalline nematic transition $(\mathrm{K} \rightarrow \mathrm{N})\left(T_{\mathrm{m}}\right)$ for the pure LCP was observed at about $228^{\circ} \mathrm{C}$ while $T_{\mathrm{m}}$ of PBT appeared at about $224^{\circ} \mathrm{C}$. Each thermogram of $5 \%$ and $10 \%$ LCP/PBT blends in Figure 1 is very similar to that of pure PBT.

(a)

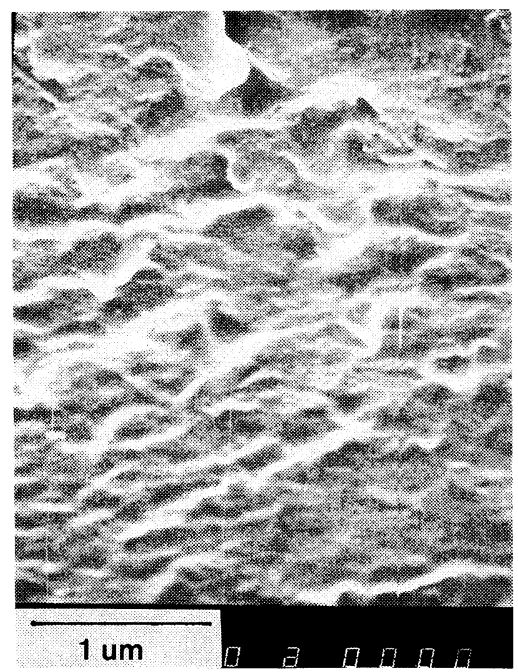

But that of $20 \%$ blend shows a small peak at $264^{\circ} \mathrm{C}$, considered to be isotropic transition temperature $\left(T_{\mathfrak{i}}\right)$ of LCP. In the case of pure LCP, isotropic transition point was observed at $270^{\circ} \mathrm{C}$. An endothermic peak corresponding to mesophase-to-isotropic liquid transition is observed in the blends containing LCP amounts higher than 20 . This behavior can be

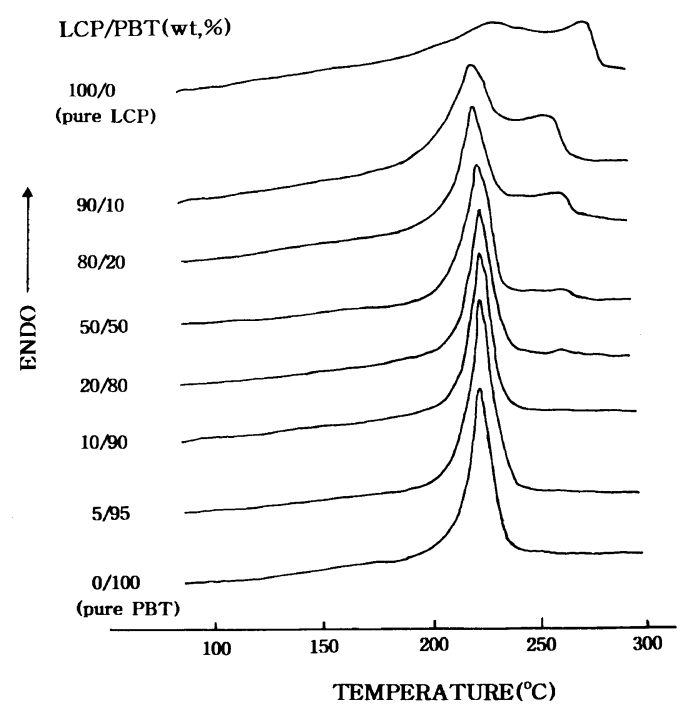

Figure 1. DSC heating thermograms for pure polymers and blends.

(b)

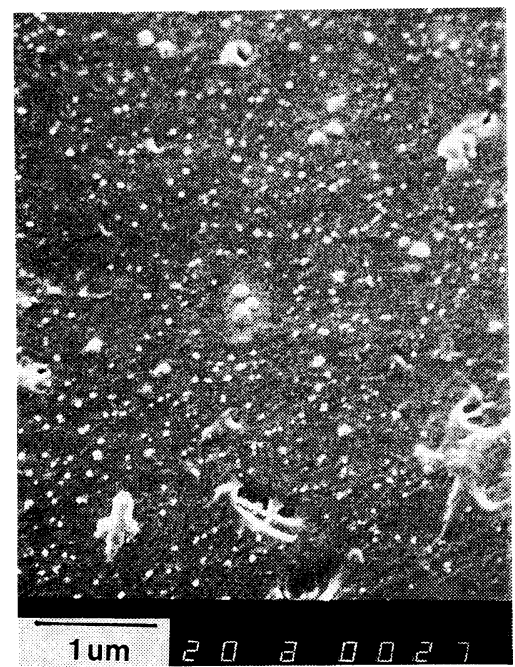

Figure 2. SEM images of LCP/PBT blends for hot pressed film. (a) $10 \%$ LCP/PBT $(30000 \times)$; (b) $20 \%$ LCP/PBT $(20000 \times)$. 
identified by SEM studies.

Figure 2 shows SEM photographs of the surfaces of the hot pressed films. Morphological changes were obvious. For $10 \%$ LCP/PBT blend film (Figure 2(a)), a uniform surface was observed. Very well dispersed white spots supposed to be LCP domains were observed for $20 \%$ LCP/PBT film (see Figure 2(b)).

Figure 3 shows a thread nematic texture for pure LCP and 90\% LCP/PBT. Poorly developed nematic texture was observed for less than $80 \mathrm{wt} \%$ LCP/PBT on Polarized Optical Microscope. However, it was expected to be liquid crystalline polymer by stir-opalescence.

The transition temperatures and enthalpy changes corresponding to melting transition are listed in Table II. The values of the glass transition temperature $\left(T_{\mathrm{g}}\right)$ of the quenched samples in liquid nitrogen at above the melting

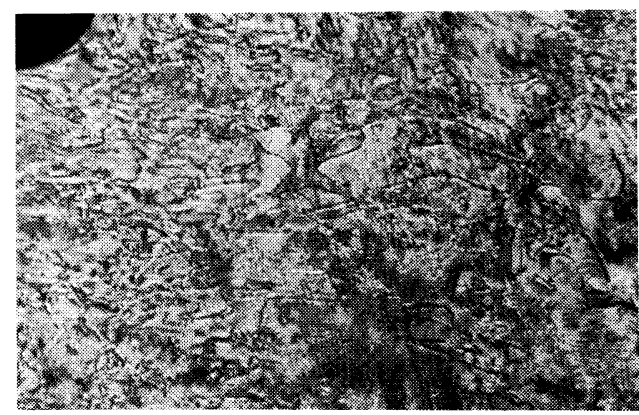

(a)

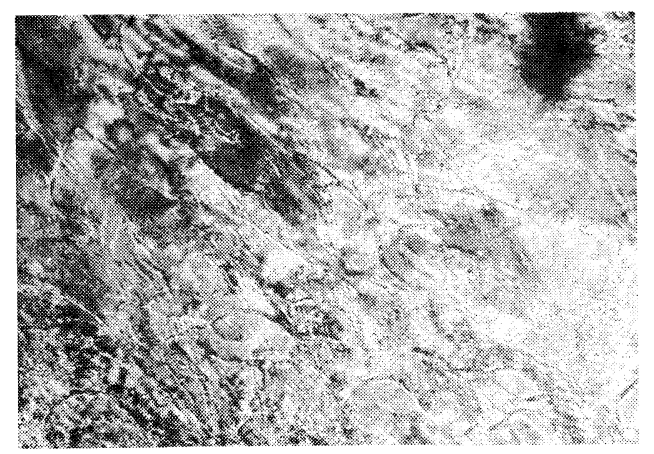

(b)

Figure 3. Optical micrographs of LCP/PBT blends $(200 \times)$. (a) $100 \% \mathrm{LCP} / \mathrm{PBT}$ at $255^{\circ} \mathrm{C}$; (b) $90 \% \mathrm{LCP} / \mathrm{PBT}$ at $253^{\circ} \mathrm{C}$. temperature $\left(T_{\mathrm{m}}\right)$ showed temperatures in range of $36-39^{\circ} \mathrm{C}$, respectively. Although low temperature ranges of the DSC thermograms of the blends are not shown, they exibited only one glass transition for all blends regardless of composition. It was impossible to observed two $T_{\mathrm{g}}$ transitions for the blends because the glass transition points of the two components were practically the same $\left(37^{\circ} \mathrm{C}\right.$ and $39^{\circ} \mathrm{C}$ for PBT and LCP, respectively). One $T_{\mathrm{g}}$ for these blends does not imply good compatibility between pure LCP and matrix.

The crystalline melting transition temperature $\left(T_{\mathrm{m}}\right)$ of pure LCP was observed at $228^{\circ} \mathrm{C}$. Copolymerization and the side-group in the rigid-rod main chain reduced the melt transition temperature. This low melting temperature is very close to the melting point $\left(224^{\circ} \mathrm{C}\right)$ of PBT. Therefore, for all blends, only one melting endotherm could be observed on DSC thermograms. Although the amount of LCP increased from 5 to $90 \mathrm{wt} \%$, the melting temperatures of all samples were also shown at $222-225^{\circ} \mathrm{C}$. The melting temperatures of the samples were not affected significantly by LCP composition in the PBT matrix.

The isotropic transition $\left(T_{\mathrm{i}}\right)$ of the blends decreased almost linearly from $264^{\circ} \mathrm{C}$ to $260^{\circ} \mathrm{C}$ with increasing LCP content up to $90 \mathrm{wt} \%$ and then increased to $270^{\circ} \mathrm{C}$ at LCP content 100

Table II. Thermal properties of pure polymers and LCP/PBT blends

\begin{tabular}{ccccc}
\hline $\begin{array}{c}\text { Blends } \\
\text { (LCP \%) }\end{array}$ & $T_{\mathrm{g}}^{\mathrm{a} /{ }^{\circ} \mathrm{C}}$ & $T_{\mathrm{m}} /{ }^{\circ} \mathrm{C}$ & $\Delta H_{\mathrm{m}}{ }^{\mathrm{b}} / \mathrm{Jg}^{-1}$ & $T_{\mathrm{i}}^{\mathrm{c}} /{ }^{\circ} \mathrm{C}$ \\
\hline 100 & 39 & 228 & 4.8 & 270 \\
$\begin{array}{c}\text { (pure LCP) } \\
90\end{array}$ & 38 & 225 & 18.5 & 260 \\
80 & 38 & 225 & 38.6 & 262 \\
50 & 38 & 224 & 46.7 & 263 \\
20 & 38 & 223 & 50.2 & 264 \\
10 & 36 & 223 & 58.8 & - \\
5 & 36 & 222 & 53.9 & - \\
0 & 37 & 224 & 48.5 & - \\
(pure PBT) & & & & \\
\hline
\end{tabular}

${ }^{a}$ Determined using quenched samples. ${ }^{b}$ Enthalpy change of fusion. ${ }^{\mathrm{c}}$ Isotropization temperature. 
(a)

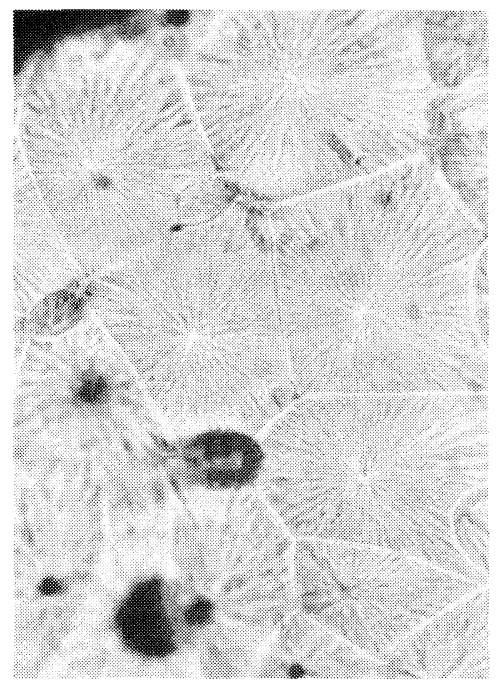

(c)

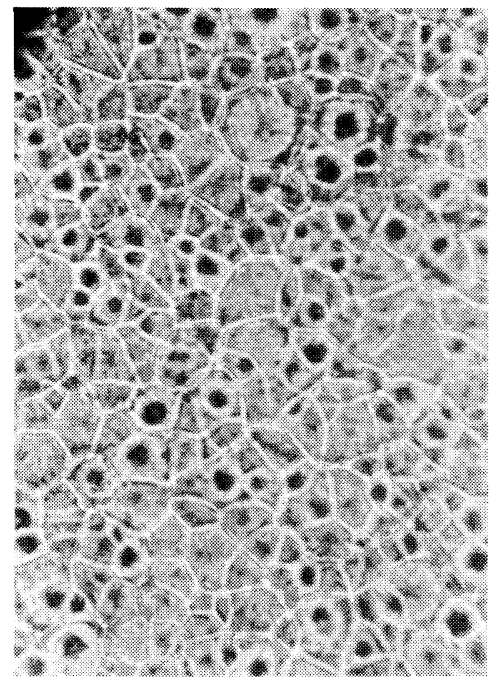

(b)

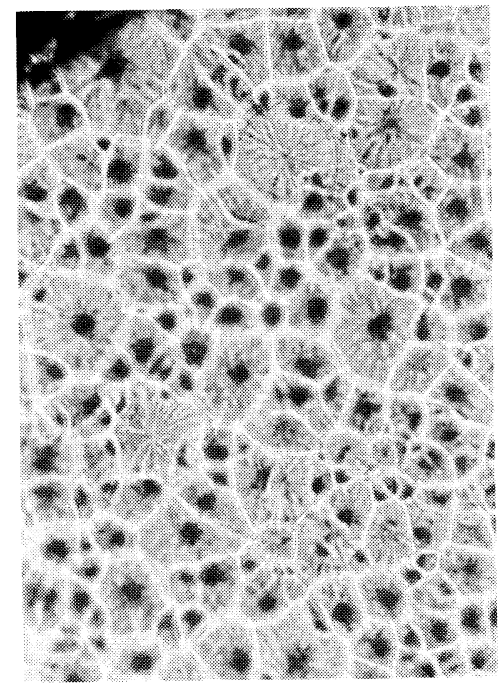

(d)

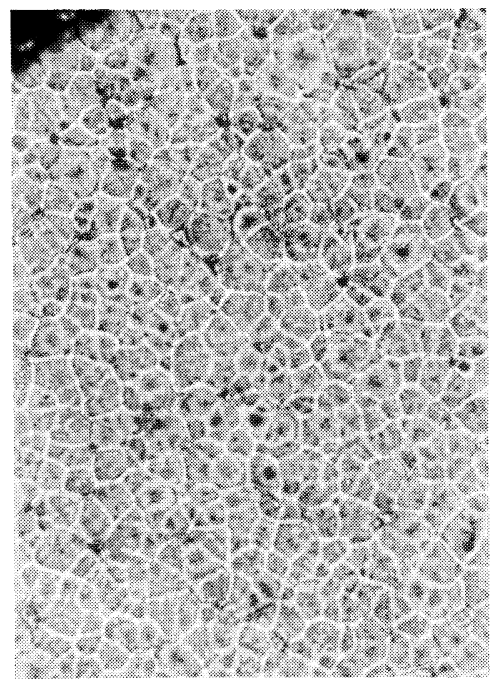

Figure 4. Optical micrographs of solvent casting films at room temperature $(200 \times)$. (a) $0 \% \mathrm{LCP} / \mathrm{PBT}$; (b) $5 \%$ LCP/PBT; (c) $10 \%$ LCP/PBT; (d) $20 \%$ LCP/PBT.

wt \% as shown in Table II. This suggests that heterogeneous two phase polyblends appears to destabilize the mesophase of the LCP component.

To examine the role of LCP in matrix polymer, solvent casting films from trifluoroacetic acid were examined by polarized optical microscope (Figure 4). For pure PBT, big domains were observed. But to increase the amount of LCP $5 \%$ to $20 \%$, the domain size of PBT becomes smaller. Thus, LCP may act as a nucleating agent for PBT matrix and there is no macrophase separation between two phases even through there is partial miscibility between these two phases; in other words, the LCP is well dispersed into the PBT matrix. Various investigators suggested that LCP acts as a nucleating agent of the matrix polymer and have reported that the rate and degree of crystallization of flexible coil polymers increase 
Table III. Results of thermogravimetric analysis of LCP/PBT blends

\begin{tabular}{ccc}
\hline $\mathrm{LCP} / \mathrm{PBT} / \mathrm{wt} \%$ & $T_{\mathrm{D}}^{\mathrm{i} \mathbf{a} /{ }^{\circ} \mathrm{C}}$ & $T_{\mathrm{D}}^{\operatorname{maxb}} /{ }^{\circ} \mathrm{C}$ \\
\hline $100 / 0$ & 291 & 397 \\
$20 / 80$ & 292 & 397 \\
$10 / 90$ & 313 & 395 \\
$5 / 95$ & 333 & 395 \\
$0 / 100$ & 334 & 400
\end{tabular}

${ }^{\mathrm{a}} T_{\mathrm{D}}^{\mathrm{i}}$, initial weight loss temp; ${ }^{\mathrm{b}} T_{\mathrm{D}}^{\max }$, maximum weight loss temp.

by the addition of LCP. ${ }^{15-17}$

The heat of fusion $\left(\Delta H_{\mathrm{m}}\right)$, in Table II, was maximum at $10 \%$ LCP and thereafter decreased with increase in LCP content in the blend. The reason is that the nucleation of the LCP phase may affect the heat of fusion of the matrix polymer. Joseph et al. ${ }^{15}$ reported similar results for blends of $60 \mathrm{~mol} \%$ PHB $-40 \mathrm{~mol} \%$ PET copolyester with PET.

The thermal stability of pure polymers and their blends under air was studied by TGA. Table III summarizes the experimental results. Initial weight loss $\left(T_{\mathrm{D}}^{\mathrm{i}}\right)$ was observed at $291-$ $334^{\circ} \mathrm{C}$ depending on the LCP weight percent in the PBT matrix. The temperatures at which the maximum rates of weight loss $\left(T_{\mathrm{D}}^{\max }\right)$ were observed were in the range of $395-400^{\circ} \mathrm{C}$. These confirm that all the samples were thermally stable at processing temperature, $245^{\circ} \mathrm{C}$.

To identify chemical reactions such as transesterification and thermal degradation during the processing at $245^{\circ} \mathrm{C}$, annealing was for $20 \% \mathrm{LCP} / \mathrm{PBT}$ blend at $250^{\circ} \mathrm{C}$ and $290^{\circ} \mathrm{C}$, respectively. DSC thermograms of the heat treated blends are shown in Figures 5 and 6. When heat treatment time increased from $5 \mathrm{~min}$ to $30 \mathrm{~min}$ at $250^{\circ} \mathrm{C}$, there was no significant change in the DSC scans. On the other hand, when annealing time at $290^{\circ} \mathrm{C}$ of the same sample inceased from 10 to $30 \mathrm{~min}$, a new peak was observed at about $175^{\circ} \mathrm{C}$ and the curve of melting temperature shifted to the lower temperature. Chemical changes thus do

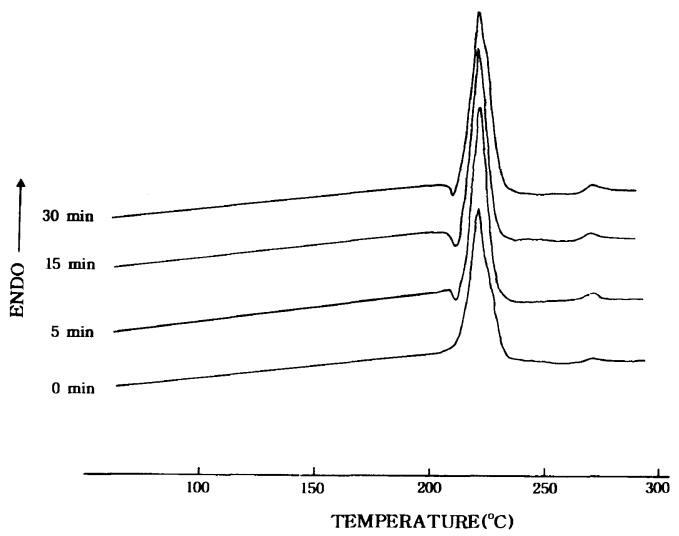

Figure 5. DSC thermogram of $20 \% \mathrm{LCP} / \mathrm{PBT}$ annealed at $250^{\circ} \mathrm{C}$ for different times.

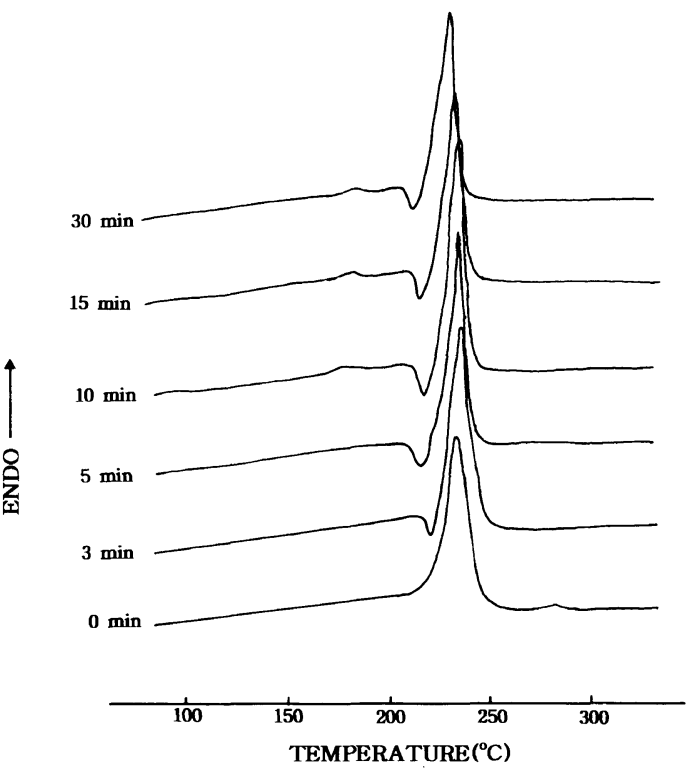

Figure 6. DSC thermogram of $20 \% \mathrm{LCP} / \mathrm{PBT}$ annealed at $290^{\circ} \mathrm{C}$ for different times.

not take place to any appreciable extent at the extrusion processing temperature $245^{\circ} \mathrm{C}$. More quantitative analysis of the chemical reactions is described by carbon-13 NMR and FT-IR elsewhere. ${ }^{18}$

\section{Mechanical Properties}

The blends and PBT were extruded into fibers through a capillary die with varying draw ratios, and the tensile strength and modulus of 
Table IV. Tensile properties of LCP/PBT extrudates ${ }^{a}$

\begin{tabular}{|c|c|c|c|}
\hline LCP content & \multirow{2}{*}{ Draw ratio } & \multirow{2}{*}{$\begin{array}{c}\text { Strength } \\
\mathrm{MPa}\end{array}$} & \multirow{2}{*}{$\frac{\text { Modulus }}{\mathrm{GPa}}$} \\
\hline$w t \%$ & & & \\
\hline 0 & 1 & 46 & 2.19 \\
\hline \multirow{3}{*}{ (pure PBT) } & 17 & 47 & 2.25 \\
\hline & 24 & 50 & 2.38 \\
\hline & 41 & 53 & 2.42 \\
\hline \multirow[t]{4}{*}{5} & 1 & 53 & 2.52 \\
\hline & 17 & 59 & 3.01 \\
\hline & 24 & 64 & 3.43 \\
\hline & 41 & 72 & 3.67 \\
\hline \multirow[t]{4}{*}{10} & 1 & 50 & 2.89 \\
\hline & 17 & 55 & 3.47 \\
\hline & 24 & 58 & 3.60 \\
\hline & 41 & 68 & 3.78 \\
\hline \multirow[t]{4}{*}{20} & 1 & 48 & 3.51 \\
\hline & 17 & 52 & 3.56 \\
\hline & 24 & 55 & 3.74 \\
\hline & 41 & 63 & $4.1 \cdot 7$ \\
\hline
\end{tabular}

${ }^{\mathrm{a}} \mathrm{L} / \mathrm{D}, 40$. Extrusion temp., $245^{\circ} \mathrm{C}$. Draw ratio $=V_{\mathrm{L}} / V_{\mathrm{O}}$. $V_{\mathrm{L}}=$ take-up speed; $V_{\mathrm{O}}=$ extrusion velocity.

the extrudates were examined. Draw ratio was calculated from the ratio of the velocity of the extrusion to the taken up speed.

Addition of LCP to the matrix polymer caused significant increase in tensile properties at each draw ratio. As shown in Table IV, the values of ultimate strength and initial modulus of the blend fibers increased remarkably with draw ratio. For 5\% LCP in the blend, for example, when the draw ratio increased from 1 to 41 , the strength and the initial modulus values increased from 53 to $72 \mathrm{MPa}$ and from 2.52 to $3.67 \mathrm{GPa}$, respectively. The increase of tensile strength and initial modulus with draw ratio was insignificant for pure PBT as usually observed in flexible coil polymers. ${ }^{19}$ For pure PBT in Table IV, the strength and modulus values increased from 46 to $53 \mathrm{MPa}$ and 2.19 to $2.42 \mathrm{GPa}$, respectively, at draw ratios from 1 to 41 . The values of the ultimate strength and initial modulus versus the draw ratio are shown in Figures 7 and 8. The mechanical properties of the extrudates did not greatly enhance for low draw ratios. But for the high

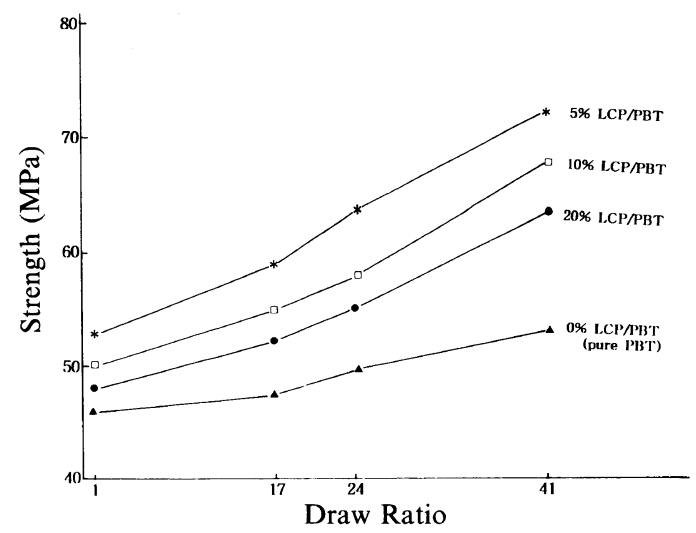

Figure 7. Effects of draw ratio on the tensile strength of LCP \%.

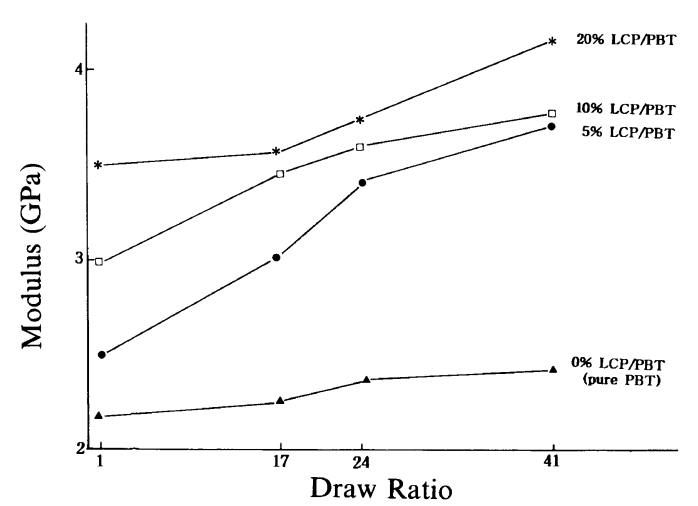

Figure 8. Effects of draw ratio on the modulus of LCP $\%$.

draw ratios the increase of strength and modulus was more. Many other investigators found that the tensile properties, strength and modulus, increased as the draw ratio increased for fibers extuded from blends of a rigid-rod LCP without flexible side-group with polycarbonates. ${ }^{20-22}$ Enhancement of the modulus due to melt drawing was a result of improved orientation and fibrillation of the dispersed LCP domains. They ${ }^{22}$ also found that the LCP chains within the domains were highly oriented in the direction of flow. Also, this could be identified by SEM in our works.

At constant draw ratio as shown in Table IV, the values of initial modulus increased with the amount of LCP in PBT matrix. In the case 


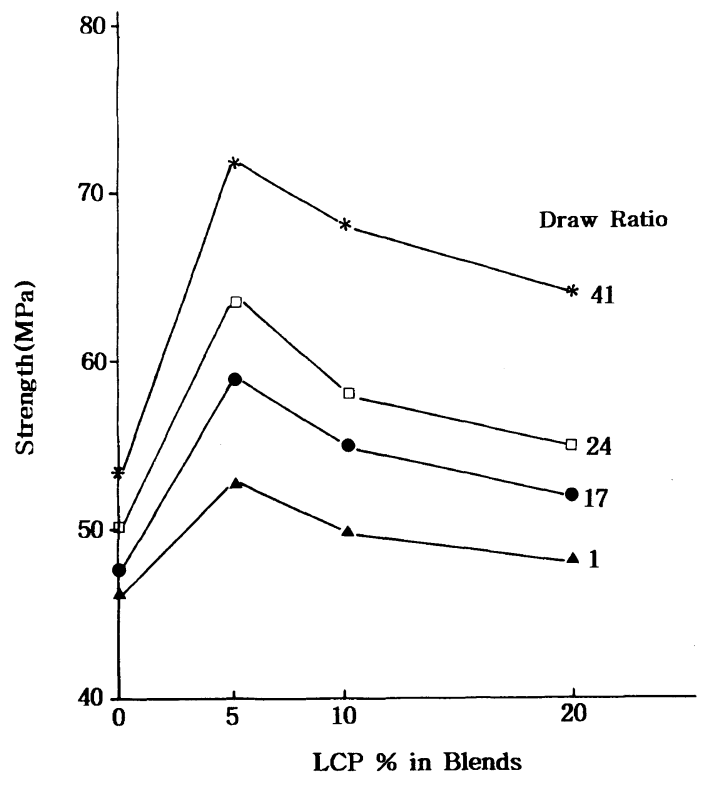

Figure 9. Effects of LCP content on tensile strength of the blends.

of draw ratio, 41 , at different LCP content, the value of the initial modulus monotonically increased from 2.42 to $4.17 \mathrm{GPa}$ (see Figure 8). Otherwise, the values of ultimate strength increased 5\% LCP content and thereafter decreased with increasing LCP percent in the blends at the same draw ratios. It thus appears that there is a critical amount of LCP beyond which the liquid crystalline polymer reinforcing capacity diminishes. For example, the value of ultimate tensile strength increased from 53 to $72 \mathrm{MPa}$ at $5 \%$ level of LCP and then decreased to $63 \mathrm{MPa}$ at LCP content of $20 \mathrm{wt} \%$ at the same draw ratio, 41 (see Table IV). Figure 9 shows the variation of the strength values versus LCP content in PBT matrix. It is suggested that the LCP molecules make large size agglomerates above $10 \%$ LCP content. This was confirmed by morphological studies by SEM as shown in Figure 10. In this blend system, the reinforcing effect did not follow that rule-of-mixtures. Similar trends have been observed with other polymer blends studied. $^{23-25}$

In conclusion, blend fibers containing 5\%
Table V. Tensile properties of 5\% LCP/PBT blend before and after heat treatment at $130^{\circ} \mathrm{C}^{\mathrm{a}}$

\begin{tabular}{rcccccc}
\hline \multirow{2}{*}{ Draw ratio } & \multicolumn{2}{c}{ Strength/MPa } & & \multicolumn{2}{c}{ Modulus/GPa } \\
\cline { 6 - 7 } \cline { 5 - 6 } \cline { 5 - 6 } & Before & After & & Before & After \\
\hline 1 & 53 & 64 & & 2.52 & 2.84 \\
17 & 59 & 75 & & 3.01 & 3.26 \\
24 & 64 & 75 & & 3.43 & 3.87 \\
41 & 72 & 81 & & 3.67 & 4.63 \\
\hline
\end{tabular}

${ }^{a}$ Annealing time was 10 hours.

LCP exibit a maximum tensile strength from $0 \%$ to $20 \%$ LCP. Initial modulus, however, increases with LCP content. These results suggest that LCP acts as a substantial reinforcement. ${ }^{22,26}$ But, compared to the many other aromatic rigid-rod LCP blends, the values of our tensile properties are not higher. ${ }^{22,27}$ This suggests that the long tri-ethoxy sidegroup improves adhesion between LCP and substrate, whereas side-groups do not maintain the rigidity of the main chain in polyblends.

Heat treatment was performed with the sample of $5 \% \mathrm{LCP} / \mathrm{PBT}$ at $130^{\circ} \mathrm{C}$ for 10 hours (Table V), and it was found that the ultimate strength and initial modulus of the undrawn fibers increased by heat treatment at each draw ratio. For a draw ratio of 41 , the values of strength and modules were improved by $9 \mathrm{MPa}$ and by $1 \mathrm{GPa}$, respectively, compared with those untreated. The improved mechanical properties may be explained by assuming transesterification in the blend. A long annealing time may yield block copolymers composed of the component polymer blocks in the blend. ${ }^{28,29}$ The block copolymers formed can act as a compatibilizer between the component polymers of the blend, resulting in improved mechanical properties. Further work is necessary to affirm this supposition. From two photographs, the dispersed LCP domains did not show significant change before and after heat treatment (not shown here). 


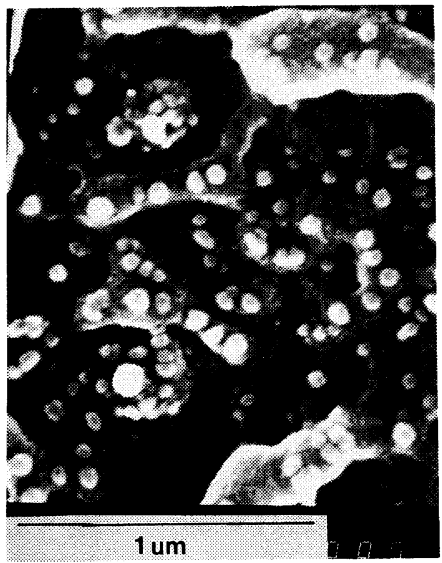

(a)

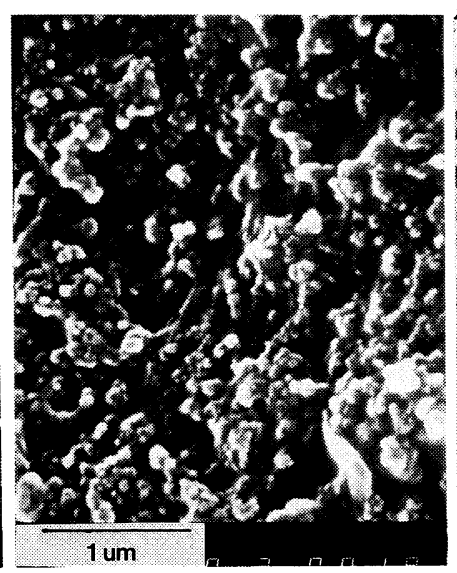

(b)

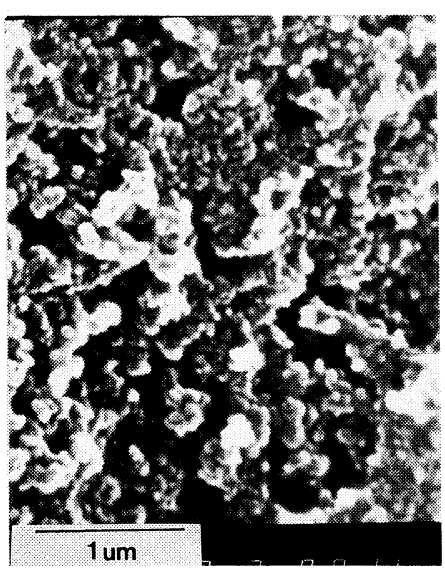

(c)

Figure 10. SEM images of the LCP/PBT blends for draw ratio=1. (a) $5 \% \mathrm{LCP} / \mathrm{PBT}(60000 \times)$; (b) $10 \%$ LCP/PBT $(30000 \times)$; (c) $20 \%$ LCP/PBT $(30000 \times)$.

\section{Morphology}

The morphology of LCP and PBT blends for undrawn fibers was examined by observing their fracture surfaces by SEM as shown in Figure 10. Based on the SEM micrographs, 5\% LCP/PBT morphology consisted of spherical LCP domains, about $40-60 \mathrm{~nm}$ in diameter, dispersed in the PBT continuous phase (Figure 10(a)). It is conceivable that the very well dispersed LCP domain increases the strength of the blends. But the LCP phase in the $10 \%$ and $20 \% \mathrm{LCP} / \mathrm{PBT}$ blends was much bigger due to agglomeration. More agglomerated LCP particles were of about $100-150 \mathrm{~nm}$ in diameter as shown in Figures 10(b) and 10(c). Similar observation was reported by Isayev $e t$ $a l^{3}$ Isayev reported that the extruded blends of an HBA/HNA and PC containing greater than $25 \mathrm{wt} \%$ LCP had spherical LCP domains dispersed in the PC matrix. But blends with $10 \%$ LCP content had fibrillar LCP morphology. It is clearly seen that the particle size of the dispersed LCP phase increases with LCP content.

As shown in Figure 11, the fractured surface of the fiber spun from the $10 \% \mathrm{LCP} / \mathrm{PBT}$ blend with a draw ratio of 24 reveals that microfibrillation is somewhat developed with

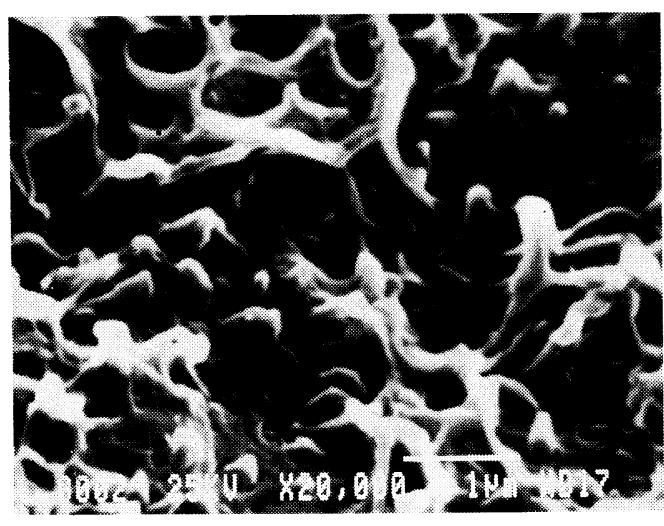

(a)

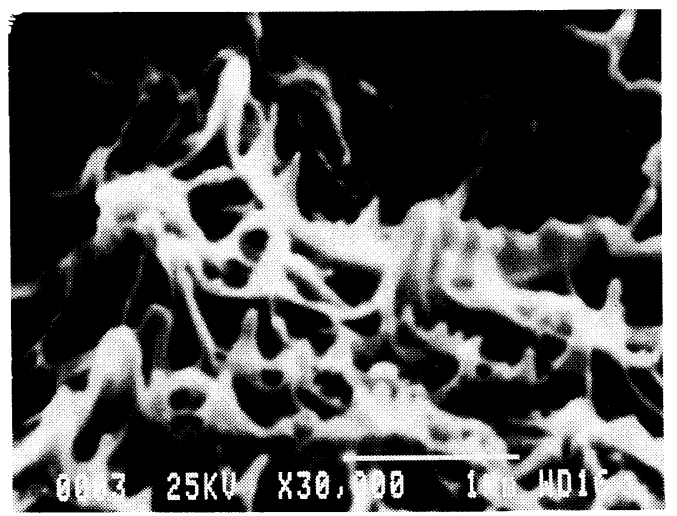

(b)

Figure 11. SEM image of $10 \% \mathrm{LCP} / \mathrm{PBT}$ blend fiber for draw ratio $=24$. (a) $20000 \times$; (b) $30000 \times$. 
well oriented fiber morphology, about $70-90$ $\mathrm{nm}$ in diameter. This indicates that enhancement of the modulus is due to improved orientation and fibrillation of the well dispersed LCP domains as mentioned above.

Adhesion between the LCP phase and matrix appears very good because we could not find open circles in the fractured surface as observed in many other blend fibers.

\section{CONCLUSION}

1. There are no chemical reactions at the processing temperature, $245^{\circ} \mathrm{C}$.

2. The values of ultimate strength lead to maximum improvement for 5\% LCP in PBT at each draw ratio, but that of the initial modulus increased with increasing the amount of LCP percent.

3. From SEM characterization of the blending fibers, it is observed that LCP is highly dispersed in the PBT matrix.

4. Annealing increases the mechanical properties of the extrudate.

Acknowledgement. The authors are thankful to the AKZO Company for financial support.

\section{REFERENCES}

1. T. Chung, Plast. Eng., 43, 39 (1987).

2. R. A. Weiss, W. Huh, and L. Nicolais, Polym. Eng. Sci., 27, 664 (1987).

3. A. I. Isayev and M. J. Modic, Polym. Compos., 8, 158 (1987).

4. G. Kiss, Polym. Eng. Sci., 27, 410 (1987).

5. K. G. Blizard and D. G. Baird, Polym. Eng. Sci., 27, 653 (1987).

6. K. Friedrich, M. Hess, and R. Kosfeld, Makromol. Chem., Macromol. Symp., 16, 251 (1988).
7. M. Ameno and K. Nakagawa, Polymer, 28, 263 (1987).

8. C. U. Ko and G. L. Wilkes, J. Appl. Polym. Sci., 37, 3063 (1989).

9. A. Kohli, N. Chung, and R. A. Weiss, Polym. Eng. Sci., 29, 573 (1989).

10. G. Sigaud, M. F. Achard, F. Hardouin, and H. Gasparous, Mol. Cryst. Lip. Cryst., 155, 443 (1988).

11. T. Heitz, P. Rohrbach, and H. Hocker, Makromol. Chem., 190, 3295 (1989).

12. A. Tendolkar, R. W. Lenz, and S. W. Kantor, unpublished results.

13. P. J. Flory, Macromolecules, 11, 1138 (1977).

14. S. M. Aharoni, Polymer, 21, 21 (1980).

15. E. G. Joseph, G. L. Wilkes, and D. G. Baird, "Polymeric Liquid Crystals," A. Blumstein, Ed., Plenum Press, New York, N.Y., 1985.

16. E. G. Joseph, G. L. Wilkes, and D. G. Baird, Am. Chem. Soc., Div. Polym. Chem., Polym. Prepr., 24, 304 (1983).

17. S. K. Bhattacharya, A. Tandolkar, and A. Misra, Mol. Cryst. Liq. Cryst., 153, 501 (1987).

18. J.-H. Chang and R. J. Farris, J. Appl. Polym. Sci., submitted for publication.

19. F. P. La Mantia, A. Valenza, M. Paci, and P. L. Magagnini, J. Appl. Polym. Sci., 38, 583 (1989).

20. P. Zhuang, T. Kyu, and J. L. White, SPEANTEC Tech. Papers, 34, 1237 (1988).

21. M. F. Froix and M. Park, U. S. Patent, $4,460,735$ (1984).

22. D. Dutta, H. Fruitwala, A. Kohli, and R. A. Weiss, Polym. Eng. Sci., 30, 1005 (1989).

23. W. J. Jackson, Jr. and H. F. Kuhfuss, J. Polym. Sci., Polym. Chem. Ed., 14, 2043 (1976).

24. A. M. Sukhadia, D. Done, and D. G. Baird, Polym. Eng. Sci., 30, 519 (1980).

25. D. G. Baird, S. S. Bafna, J. P. Desouza, and T. Sun, Polym. Compos., 14, 214 (1993).

26. T. M. Malik, P. J. Carreau, and N. Chapleau, Polym. Eng. Sci., 29, 600 (1989).

27. F. P. La Mantia, "Thermotropic Liquid Crystal Polymer Blends," Technomic Press, Lancaster, PA, 1993, Chapter 5.

28. R. S. Porter, J. M. Jonza, M. Kimura, C. R. Desper, and E. R. George, Polym. Eng. Sci., 29, 55 (1989).

29. M. Cortazar, J. I. Eguiazable, and J. J. Iruin, Eur. Polym. J., 30, 901 (1994). 